\title{
Fertility-sparing Surgery for Presumed Early-stage Invasive Cervical Cancer: A Survey of Practice in the United Kingdom
}

\author{
MENELAOS TZAFETAS ${ }^{1,2}$, ANITA MITRA ${ }^{1,2}$, ILKKA KALLIALA ${ }^{1,3}$, \\ SARAH LEVER ${ }^{1,2}$, CHRISTINA FOTOPOULOU $^{2}$, ALAN FARTHING $^{2}$, JOHN RICHARD SMITH $^{2}$, \\ PIERRE MARTIN-HIRSCH ${ }^{4}$, EVANGELOS PARASKEVAIDIS ${ }^{5}$ and MARIA KYRGIOU ${ }^{1,2}$ \\ ${ }^{1}$ Institute of Reproductive and Developmental Biology, Surgery and Cancer, Imperial College London, London, U.K.; \\ ${ }^{2}$ West London Gynaecological Cancer Centre, Hammersmith Hospital, \\ Imperial College Healthcare NHS Trust, London, U.K.; \\ ${ }^{3}$ Department of Obstetrics and Gynaecology, \\ Helsinki University and University Hospital Helsinki, Helsinki, Finland; \\ ${ }^{4}$ Department of Obstetrics and Gynaecology, \\ Lancashire Teaching Hospitals NHS Foundation Trust, Lancaster, U.K.; \\ ${ }^{5}$ Department of Obstetrics and Gynaecology, University of Ioannina, Ioannina, Greece
}

\begin{abstract}
Aim: To explore current practice in fertilitysparing surgery for cervical cancer in the UK. Materials and Methods: A web-based structured questionnaire was designed and circulated to all members of the British Gynaecological Cancer Society. Results: From 111 recipients, a total of 49 responses were collected. The majority of centres treated between 20-29 cases of invasive cervical cancer surgically $(21 / 49,42.9 \%)$ and performed between 0-5 cases of radical trachelectomy annually (29/49, $59.2 \%)$. The vaginal approach was the one most commonly used and was offered by almost half of the centres (21/49, 42.9\%); laparoscopic techniques were offered in 13 (13/49, $26.6 \%)$. The responses were divided as to whether these cases should have been referred to supra-regional centres (25/49, 51.0\%). Conclusion: With the use of Human Papillomavirus vaccination leading to a projected decrease in the number of cervical cancer incidence, patients may need to be referred to supraregional centres in the future.
\end{abstract}

Cervical cancer remains the second commonest female malignancy in developed countries (1). The disease primarily affects young sexually active women with more than $25 \%$ of

Correspondence to: Maria Kyrgiou, M.Sc., Ph.D., MRCOG, Department of Surgery and Cancer, IRDB, 3rd Floor, Imperial College London, Hammersmith Campus, Du Cane Road, W12 0NN, London, U.K. Tel: +44 2075942177, e-mail: m.kyrgiou@imperial.ac.uk

Key Words: Invasive cervical cancer, radical trachelectomy, radical hysterectomy, fertility. cases being diagnosed in women under the age of 40 years $(2,3)$. Therefore, the total years of life lost is proportionately higher than that for most other cancer types with a later onset. With the advent of screening, the majority of cervical cancer cases in developed countries are diagnosed at early stages with small-volume disease that presents different challenges. With the age of women at their first childbirth increasing continuously in Western societies, fertility-sparing options that minimize reproductive morbidity present challenges for healthcare providers.

The concept of fertility-sparing surgery in presumed early cervical cancer was first introduced by Professor Dargent in 1986 with the first publication of the results from radical vaginal trachelectomy with laparoscopic lymphadenectomy in 1994 (4). Three years later, Smith, Ungar and Del Priore introduced an abdominal open approach to the procedure, radical abdominal open trachelectomy (RAOT) (5), an approach surgically more familiar to gynaecological oncologists (6). More recently, laparoscopic and robotic approaches have been introduced, reducing morbidity and improving recovery time $(7,8)$.

It is now thought that the oncological outcomes of radical trachelectomy are similar to that of radical hysterectomy in well-selected cases $(3,6,9)$. Both the vaginal and abdominal techniques are now considered to be safe fertility-sparing procedures in cases with tumours less than $2 \mathrm{~cm}$ in size (3), whilst Smith et al. recommend that RAOT is suitable for tumours up to $4 \mathrm{~cm}$ as the abdominal approach allows more radical excision of the parametrium which is possibly compromised by the vaginal route (6). The radicality of the trachelectomy technique can, however, adversely affect the 
rate of pregnancy and live birth, with abdominal trachelectomy performing worse than vaginal approach (3).

The need to remove the parametrial tissue as part of the procedure can damage the autonomic nerves and result in associated morbidity such as bladder disorders, sexual dysfunction and colorectal motility disorders (10). The concept of preserving the autonomic nerve plexus in radical hysterectomy has become standard in most centres, and has expanded to radical trachelectomy techniques (11). These specialized nerve-sparing techniques require appropriately trained surgeons and an appropriate annual workload for skill preservation (12). The number of invasive cervical cancer cases has decreased significantly with organised screening and is expected to further diminish with national Human Papillomavirus (HPV) vaccination programmes (13). With most centres in the UK only performing a handful of cases annually, the concept of specialized supraregional centres is frequently debated.

There is ongoing debate regarding the need for parametrectomy in small-volume, low-risk early cervical cancer cases (stage $1 \mathrm{a} 2$ and small 1b1). With the Simple Hysterectomy and Pelvic node dissection in Early Cervical Cancer (SHAPE) trial (CRUK/13/015) currently randomizing women to simple or radical hysterectomy for these tumours, the results are expected to affect how fertilitysparing cases are managed. Less radical approaches in the form of simple trachelectomy or even conisation may replace currently used techniques (14-18). Previous retrospective studies report similar oncological and pregnancy outcomes to those of radical trachelectomy $(3,15-18)$.

The aim of this survey was to explore current practice in fertility-sparing surgery for cervical cancer in the UK, with particular emphasis on the workload and factors affecting the choice of the technique used.

\section{Materials and Methods}

We designed a web-based survey comprising of 10 questions enquiring about the current practice regarding fertility-sparing surgical approaches for early-stage invasive cervical cancer in the UK. The survey was circulated via the administration of an anonymous, non-validated, commercially available online survey (Survey Monkey ${ }^{\mathrm{TM}}$ ). The questions included were reviewed and approved by the British Gynaecological Cancer Society (BGCS) Committee. The e-mail inviting participation was sent to all members (359) with working e-mails across specialties, 111 received the survey (gynaecological oncologists, clinical and medical oncologists, radiologists, pathologists, clinical nurse specialists and other allied professionals, including scientists with an interest in gynaecological cancer). The questions are shown in Tables I and II.

The data were collected, analysed and extracted using the Survey Monkey ${ }^{\mathrm{TM}}$ database. Further graphs and analysis were performed with Microsoft Office Excel. Percentages were calculated based on the total number of survey participants and the number of responses to each individual question.

\section{Results}

Replies were collected from a total of 49 BGCS members (Tables I and II).

There was good representation of responses across the UK. Out of the demographic distribution of the BGCS members that participated in the survey, the lowest number was from Wales $(5 / 49,10.2 \%)$ and the highest from London $(7 / 49,14.3 \%)$. The remaining responses ranged from 8.2 to $12.2 \%$ across the different geographical locations within the UK (Table I). The majority of the centres treated between 20-29 cases of invasive cervical cancer surgically $(21 / 49,42.9 \%)$. Only 10 of the participants $(10 / 49,20.4 \%)$ reported a workload of more than 40 new cases annually, whilst one centre treated fewer than nine cases $(1 / 49,2.0 \%)$ and another eight $(8 / 49,16.3 \%)$ between 10-19 annually (Table I). When asked about the proportion of radical hysterectomies performed with minimally invasive techniques, only 11 centres $(11 / 49,22.5 \%)$ responded that minimally invasive techniques were used for all radical hysterectomies, approximately one-third for more than $50 \%$ of the cases $(19 / 49,38.8 \%)$, whilst six centres did not offer such an approach to surgery for radical hysterectomies $(6 / 49,12.2 \%)$ (Table I). Approximately half of the centres were planning to recruit in the SHAPE trial $(25 / 49,51 \%)$, whilst one in 10 participants had not even heard about the trial $(6 / 49,12.2 \%)$ (Table I).

The majority of centres considered a workload of between 0-5 cases suitable for radical trachelectomy every year (29/49, $59.2 \%$ ), almost one-fifth of the centres between 6-10 cases $(9 / 49,18.4 \%)$, whilst only three centres had more than 15 cases annually $(3 / 49,6.1 \%)$ (Table II). When asked about the surgical workload of trachelectomies per individual surgeon, approximately one-third performed between $2-5$ cases $(14 / 49$, $28.6 \%)$, only six $(6 / 49,12.2 \%)$ performed more than five cases per year and three $(3 / 49,6.1 \%)$ only one case annually. Almost half reported that they do not perform any trachelectomies, although in half of the cases the centre did offer the procedure $(14 / 49,28.6 \%)$ (Table II). The vaginal approach was the most commonly used technique and was offered by almost half of the centres $(21 / 49,42.9 \%)$. Laparoscopic techniques were offered in $13(13 / 49,26.6 \%)$. One in 10 offered only the open procedure $(5 / 49,10.2 \%)$ (Table II).

The presence of disease close to the superior soft-tissue margin in magnetic resonance imaging was the commonest reason preventing trachelectomy $(23 / 49,46.9 \%)$, followed by the presence of lymphovascular space invasion $(11 / 49$, $22.5 \%)$, and poor differentiation $(8 / 49,16.3 \%)$. The presence of adenocarcinoma was reported as being a contraindication to performing radical trachelectomy in five centres $(5 / 49$, $10.2 \%$ ) (Table II). The vast majority of the centres offered simple conisation and lymphadenectomy in selected cases of stage Ia 2 and Ib1 disease $(41 / 49,83.7 \%)$, whilst one in 10 centres never offered this approach $(6 / 49,12.2 \%)$. Most 
Table I. Survey questionnaire and outcomes - Demographics and Workload. British Gynaecological Cancer Society member survey, total responders $=49$.

\begin{tabular}{lc}
\hline Question & $\mathrm{n}(\%)$ \\
\hline Where is your Gynaecological Cancer Centre based? & \\
London & $7(14.3)$ \\
South West & $4(8.2)$ \\
South East & $6(12.2)$ \\
Midlands & $5(10.2)$ \\
North West & $5(10.2)$ \\
North East & $6(12.2)$ \\
Wales & $2(4.1)$ \\
Scotland & $5(10.2)$ \\
Other & $9(18.4)$ \\
How many cases of ICC are treated in & \\
your centre surgically every year? & \\
$0-9$ & $1(2.0)$ \\
$10-19$ & $8(16.3)$ \\
20-29 & $21(42.9)$ \\
$30-39$ & $6(12.2)$ \\
$>40$ & $10(20.4)$ \\
Not answered & $3(6.1)$ \\
What proportion of RH are done & \\
laparoscopically or robotically? & \\
All & \\
$>50 \%$ & $11(22.5)$ \\
10-50\% & $19(38.8)$ \\
1-9\% & $7(14.3)$ \\
None & $3(26.6)$ \\
Not answered & $3(6.1)$ \\
Do you believe that RT should be referred & $6(12.2)$ \\
Yes supra-regional centres? & $3(6.1)$ \\
No & \\
I do not know & \\
Not answered & $25(51.0)$ \\
Are you planning to recruit in the SHAPE trial that \\
will randomize low-volume cervical cancers into \\
surgical management with simple versus radical \\
hysterectomy with lymphadenectomy? \\
Yes & $21(42.9)$ \\
No & $2(4.1)$ \\
Not aware of the trial & \\
Not answered & \\
\hline & \\
\hline
\end{tabular}

ICC: Invasive cervical cancer; RH: radical hysterectomy; RT: radical trachelectomy; SHAPE: Simple Hysterectomy and Pelvic node dissection in Early cervical cancer.

centres offered simple conisation and lymphadenectomy in both stages $(25 / 49,51.0 \%)$, whilst $15(15 / 49,30.7 \%)$ only in stage $1 \mathrm{a} 2$ disease (Table II).

The responses as to whether these cases of early-stage invasive cervical cancer should be referred to supra-regional centres was split amongst participants, with 25 responding favourably to the creation of such centres $(25 / 49,51 \%)$; one was undecided $(1 / 49,2.0 \%)$.
Table II. Survey questionnaire and outcomes - Surgical procedures and preferences. British Gynaecological Cancer Society member survey, total responders $=49$.

Question n (\%)

How many cases of ICC treated surgically in

your centre are considered for RT?

None $1(2.0)$

$0-5 \quad 29(59.2)$

6-10 $9(18.4)$

11-15 $4(8.2)$

$>15 \quad 3(6.1)$

Not answered $3(6.1)$

If you perform RT in your centre, which surgical

approach(es) do you use? (more than one can be chosen)

Abdominal open $5(10.2)$

Abdominal laparoscopic $9(18.4)$

Abdominal robotic $2(4.1)$

Vaginal 16 (32.7)

Abdominal open or vaginal $1(2.0)$

Abdominal laparoscopic or vaginal 3 (6.1)

Abdominal open or laparoscopic or vaginal $1(2.0)$

Not performed in the centre $9(18.4)$

Not Answered $3(6.1)$

How many trachelectomies do you

perform as a surgeon every year?

None (centre does not perform RT) $10(20.4)$

None (centre performs RT) 14 (28.6)

1 3(6.1)

$2-5 \quad 14(28.6)$

$>5 \quad 6(12.2)$

Not answered 2 (4.1)

If you perform radical trachelectomies in your

centre, in early stage $1 \mathrm{~B} 1 \mathrm{ICC},<2 \mathrm{~cm}$ in size, what

characteristics would prevent you from performing

a RT? (more than one can be chosen)

Parity $\geq 1 \quad 0(0)$

Positive LVSI $11(22.5)$

Poor differentiation $\quad 8(16.3)$

Disease close to superior soft tissue on MRI 23 (46.9)

Adenocarcinoma $5(10.2)$

Not answered 14 (28.6)

Other $5(10.2)$

Does your unit offer simple conisation and

PLND in low volume stage IA2-IB1 ICC?

Yes, in some cases of stage 1A2 and 1B1 disease $25(51.0)$

Yes, but only in some cases of stage 1A2 disease $15(30.7)$

Yes, but only in some cases of stage 1B1 disease $1(2.0)$

No

$6(12.2)$

Not answered $2(4.1)$

ICC: Invasive cervical cancer; RT: radical trachelectomy; PLND: pelvic lymph node dissection.

\section{Discussion}

Main finding in light of other evidence. Management for cervical cancer presents several challenges. Currently offered treatment options with curative intent should aim to combine high oncological efficacy with minimum morbidity. The 
mean age at diagnosis for cervical cancer is substantially lower than in other gynaecological malignancies and the long-term side-effects of treatment may significantly affect the patient's future quality of life. In the UK, over 1,000 women with cervical cancer, 120 with endometrial cancer and over 500 with ovarian cancer will be diagnosed before the age of 45 years annually (19). One in four women diagnosed with cervical cancer are below the age of 40 years (20). With women progressively delaying conception in Western societies, fertility preservation and reduced morbidity become major challenges in the management of young women with this disease.

In our survey, which represented the whole of the UK, we found that the majority of centres treated between 20-29 cases annually and only one in five centres had more than 40 cases. The vast majority offered a laparoscopic approach to radical hysterectomy. The majority of centres considered fewer than five patients a year for fertility-sparing surgery with radical trachelectomy. One-third of surgeons performed between two to five cases and only one in 10 more than five annually. Half of the surgeons did not perform the procedure and one in five centres referred patients to other referral units for the procedure. The vaginal approach was the most commonly used technique, while only one in four centres offered a laparoscopic approach. One in 10 only performed open procedures.

There has been debate with regards to the optimal surgical approach to radical trachelectomy (3). Some authors advocate that the open abdominal approach allows more radical resections, better clearance of lymph nodes and length of parametria, with the additional advantage of a more familiar operating approach, as experience in laparoscopy and advanced vaginal surgery is not required $(5,21)$. Opponents hold the opinion that oncological outcomes are not compromised as reports support equivalence of recurrence rates, whilst lower success rates may be noted in fertility outcomes (22-24). With increasing evidence suggesting that parametrectomy may not be required in selected cases of small-volume low-risk early cervical tumours $(17,25-28)$, less radical techniques that include simple trachelectomy or even conisation may replace radical trachelectomy and further improve future reproductive outcomes (29-31). Evidence from the SHAPE trial is awaited and results are likely to expand to fertility-sparing treatments. Conversely, when the procedure is conducted for larger tumours $(>2 \mathrm{~cm})$, the open abdominal approach allowing more radical excision of the parametrium is likely to be the treatment of choice (6).

Furthermore, the use of neodjuvant chemotherapy for larger volume tumours may allow the expansion of fertilitysparing techniques to patients previously treated with radical hysterectomy with/without radiotherapy. This approach has the potential to improve oncological outcomes for patients with larger tumours without compromising their pregnancy outcomes. There have been several studies showing there is a promising future for this approach, however, it is still in an experimental stage and further trials are needed (32-35).

There has been substantial evidence that centralized care of gynaecological cancer patients at referral centres is associated with improved outcomes and survival $(36,37)$. There is an ongoing debate regarding gynaecological cancer as to whether rare tumours and surgical procedures requiring more specialized training should be referred to supra-regional centres in the hands of a few highly skilled surgeons. Suggested procedures include radical trachelectomy and ultra-radical surgery for ovarian cancer $(38,39)$. Our survey suggested that the opinions are split amongst clinicians, with half advocating supra-regional care. With increasing emphasis on nerve-sparing surgical techniques, which require advanced training $(10,11$, 40) and an anticipated decrease in the number of cervical cancer cases following vaccination (13), the argument about supra-regional care in cervical cancer is becoming stronger. Advocates support higher success rates when the service is offered by a dedicated team of surgeons $(37-39,41)$, while opponents support the impact of lost skills in regional hospitals and the difficulties for patients in accessing supra-regional centres (42).

The optimal antenatal management for women after trachelectomy is difficult to establish due to the rarity of the procedure. Previous studies suggested preterm birth rates in such women to be as high as $38 \%$ (23). The risk of preterm birth has been reported to be higher for vaginal (18.8\%) as opposed to abdominal approaches (23.3\%) (3). The incidence of preterm birth is inversely correlated with the cervical length remaining (43-48), which can make women more vulnerable to ascending infections, preterm rupture of membranes and preterm birth. Previous research suggested that leaving at least $1 \mathrm{~cm}$ of healthy cervical tissue at the time of radical trachelectomy may improve outcomes at a later gestation $(49,50)$.

Strengths and limitations of the study. To our knowledge, this is the first study to report a survey on the views and practices in cervical cancer surgery across the UK. We were able to collect a representative sample from healthcare professionals and obtain a snapshot of the differences in management with an emphasis on fertility-sparing techniques. There were also limitations. The number of responders was only a fraction of the members of the society and their exact job title was not available. The different specialty of the participants may have therefore introduced bias. Furthermore, variations in the case mix, stage and presentation of cases could have been a further source of bias.

\section{Conclusion}

With optimal oncological efficacy and minimal morbidity being one of the major challenges in the treatment of cervical 
cancer, this survey provides insight into the practices in surgical management across the UK. Good selection of cases that are offered fertility-sparing techniques is required. With a decreasing number of cases due to screening and further projected decreases with vaccination against HPV, cervical cancer will become a rare tumour type. Although most centres in the UK offer the breadth of surgical procedures, supra-regional centres may be required in the future.

\section{Acknowledgements}

The Authors thank all health professionals that responded to the survey.

\section{References}

1 Arbyn M, Autier P and Ferlay J: Burden of cervical cancer in the 27 member states of the European Union: estimates for 2004. Ann Oncol 18: 1423-1425, 2007.

2 Watson M, Saraiya M, Benard V, Coughlin SS, Flowers L, Cokkinides V, Schwenn M, Huang Y and Giuliano A: Burden of cervical cancer in the United States, 1998-2003. Cancer 113: 2855-2864, 2008.

3 Rob L, Skapa P and Robova H: Fertility-sparing surgery in patients with cervical cancer. Lancet Oncol 12: 192-200, 2011.

4 Dargent D, Brun JL, Roy M and Remy I: Pregnancies following radical trachelectomy for invasive cervical cancer (Abstract). Gynecol Oncol 52: 105, 1994.

5 Smith JR, Boyle DC, Corless DJ, Ungar L, Lawson AD, Del Priore G, McCall JM, Lindsay I and Bridges JE: Abdominal radical trachelectomy: a new surgical technique for the conservative management of cervical carcinoma. Br J Obstet Gynaecol 104: 1196-1200, 1997.

6 Saso S, Ghaem-Maghami S, Chatterjee J, Naji O, Farthing A, Mason P, McIndoe A, Hird V, Ungar L, Del Priore G and Smith JR: Abdominal radical trachelectomy in West London. BJOG 119: 187-193, 2012.

7 Burnett AF, Stone PJ, Duckworth LA and Roman JJ: Robotic radical trachelectomy for preservation of fertility in early cervical cancer: case series and description of technique. J Minim Invasive Gynecol 16: 569-572, 2009.

8 Kyrgiou M, Horwell DH and Farthing A: Laparoscopic radical abdominal trachelectomy for the management of stage IB1 cervical cancer at 14 weeks' gestation: case report and review of the literature. BJOG 122: 1138-1143, 2015.

9 Covens A, Shaw P, Murphy J, DePetrillo D, Lickrish G, Laframboise $\mathrm{S}$ and Rosen $\mathrm{B}$ : Is radical trachelectomy a safe alternative to radical hysterectomy for patients with stage IA-B carcinoma of the cervix? Cancer 86: 2273-2279, 1999.

10 Park NY, Chong GO, Cho YL, Park IS and Lee YS: Total laparoscopic nerve-sparing radical trachelectomy. J Laparoendosc Adv Surg Tech A 19: 53-58, 2009.

11 Rob L, Halaska $M$ and Robova $H$ : Nerve-sparing and individually tailored surgery for cervical cancer. Lancet Oncol 11: 292-301, 2010.

12 Saadi JM, Perrotta M, Orti R, Salvo G, Giavedoni ME, Gogorza $\mathrm{S}$ and Testa R: Laparoscopic radical trachelectomy: technique, feasibility and outcomes. JSLS 19: e2013 00248, 2015.
13 Castanon A, Landy R, Pesola F, Windridge P and Sasieni P: Prediction of cervical cancer incidence in England, UK, up to 2040, under four scenarios: a modelling study. Lancet Public Health 3: e34-e43, 2018.

14 Kim M, Ishioka S, Endo T, Baba T, Mizuuchi M, Takada S and Saito T: Possibility of less radical treatment for patients with early invasive uterine cervical cancer. J Obstet Gynaecol Res 42: 876-882, 2016.

15 Ditto A, Martinelli F, Bogani G, Fischetti M, Di Donato V, Lorusso D and Raspagliesi F: Fertility-sparing surgery in earlystage cervical cancer patients: oncologic and reproductive outcomes. Int J Gynecol Cancer 25: 493-497, 2015.

16 Biliatis I, Kucukmetin A, Patel A, Ratnavelu N, Cross P, Chattopadhyay S, Galaal K and Naik R: Small volume stage 1B1 cervical cancer: Is radical surgery still necessary? Gynecol Oncol 126: 73-77, 2012.

17 Baiocchi G, de Brot L, Faloppa CC, Mantoan H, Duque MR, Badiglian-Filho L, da Costa $\mathrm{A}$ and Kumagai LY: Is parametrectomy always necessary in early-stage cervical cancer? Gynecol Oncol 146: 16-19, 2017.

18 Okugawa K, Kobayashi H, Sonoda K, Kaneki E, Kawano Y, Hidaka N, Egashira K, Fujita Y, Yahata $\mathrm{H}$ and Kato K: Oncologic and obstetric outcomes and complications during pregnancy after fertility-sparing abdominal trachelectomy for cervical cancer: a retrospective review. Int J Clin Oncol 22: 340346, 2017.

19 Farthing A: Conserving fertility in the management of gynaecological cancers. BJOG 113: 129-134, 2006.

20 Sonoda Y, Abu-Rustum NR, Gemignani ML, Chi DS, Brown CL, Poynor EA and Barakat RR: A fertility-sparing alternative to radical hysterectomy: how many patients may be eligible? Gynecol Oncol 95: 534-538, 2004.

21 Einstein MH, Park KJ, Sonoda Y, Carter J, Chi DS, Barakat RR and Abu-Rustum NR: Radical vaginal versus abdominal trachelectomy for stage IB1 cervical cancer: a comparison of surgical and pathologic outcomes. Gynecol Oncol 112: 73-77, 2009.

22 Cao DY, Yang JX, Wu XH, Chen YL, Li L, Liu KJ, Cui MH, Xie X, Wu YM, Kong BH, Zhu GH, Xiang Y, Lang JH, Shen K and China Gynecologic Oncology G: Comparisons of vaginal and abdominal radical trachelectomy for early-stage cervical cancer: preliminary results of a multi-center research in China. Br J Cancer 109: 2778-2782, 2013.

23 Bentivegna E, Maulard A, Pautier P, Chargari C, Gouy S and Morice P: Fertility results and pregnancy outcomes after conservative treatment of cervical cancer: a systematic review of the literature. Fertil Steril 106: 1195-1211 e1195, 2016.

24 Bentivegna E, Gouy S, Maulard A, Chargari C, Leary A and Morice P: Oncological outcomes after fertility-sparing surgery for cervical cancer: a systematic review. Lancet Oncol 17: e240e253, 2016

25 Strnad P, Robova H, Skapa P, Pluta M, Hrehorcak M, Halaska $M$ and Rob L: A prospective study of sentinel lymph node status and parametrial involvement in patients with small tumour volume cervical cancer. Gynecol Oncol 109: 280-284, 2008.

26 Covens A, Rosen B, Murphy J, Laframboise S, DePetrillo AD, Lickrish G, Colgan T, Chapman W and Shaw P: How important is removal of the parametrium at surgery for carcinoma of the cervix? Gynecol Oncol 84: 145-149, 2002. 
27 Stegeman M, Louwen M, van der Velden J, ten Kate FJ, den Bakker MA, Burger CW and Ansink AC: The incidence of parametrial tumor involvement in select patients with early cervix cancer is too low to justify parametrectomy. Gynecol Oncol 105: 475-480, 2007.

28 Rob L, Strnad P, Robova H, Charvat M, Pluta M, Schlegerova D and Hrehorcak M: Study of lymphatic mapping and sentinel node identification in early stage cervical cancer. Gynecol Oncol 98: 281-288, 2005.

29 Fagotti A, Gagliardi ML, Moruzzi C, Carone V, Scambia G and Fanfani F: Excisional cone as fertility-sparing treatment in earlystage cervical cancer. Fertil Steril 95: 1109-1112, 2011.

30 Rob L, Pluta M, Strnad P, Hrehorcak M, Chmel R, Skapa P and Robova H: A less radical treatment option to the fertility-sparing radical trachelectomy in patients with stage I cervical cancer. Gynecol Oncol 111: S116-120, 2008.

31 Rob L, Charvat M, Robova H, Pluta M, Strnad P, Hrehorcak M and Skapa $P$ : Less radical fertility-sparing surgery than radical trachelectomy in early cervical cancer. Int J Gynecol Cancer 17: 304-310, 2007.

32 Landoni F, Parma G, Peiretti M, Zanagnolo V, Sideri M, Colombo N and Maggioni A: Chemo-conization in early cervical cancer. Gynecol Oncol 107: S125-126, 2007.

33 Maneo A, Chiari S, Bonazzi C and Mangioni C: Neoadjuvant chemotherapy and conservative surgery for stage IB1 cervical cancer. Gynecol Oncol 111: 438-443, 2008.

34 Plante M, Lau S, Brydon L, Swenerton K, LeBlanc R and Roy M: Neoadjuvant chemotherapy followed by vaginal radical trachelectomy in bulky stage IB1 cervical cancer: case report. Gynecol Oncol 101: 367-370, 2006.

35 Robova H, Pluta M, Hrehorcak M, Skapa P and Rob L: Highdose density chemotherapy followed by simple trachelectomy: full-term pregnancy. Int J Gynecol Cancer 18: 1367-1371, 2008.

36 Woo YL, Kyrgiou M, Bryant A, Everett T and Dickinson HO: Centralisation of services for gynaecological cancer. Cochrane Database Syst Rev: CD007945, 2012.

37 Brand AH: Jack of all trades, master of none? The need for centralisation of services for rarely performed procedures. Aust N Z J Obstet Gynaecol 55: 298, 2015.

38 Crawford $\mathrm{R}$ and Greenberg D: Improvements in survival of gynaecological cancer in the Anglia region of England: are these an effect of centralisation of care and use of multidisciplinary management? BJOG 119: 160-165, 2012.

39 Sullivan R, Alatise OI anderson BO, Audisio R, Autier P, Aggarwal A, Balch C, Brennan MF, Dare A, D'Cruz A, Eggermont AM, Fleming K, Gueye SM, Hagander L, Herrera CA, Holmer H, Ilbawi AM, Jarnheimer A, Ji JF, Kingham TP, Liberman J, Leather AJ, Meara JG, Mukhopadhyay S, Murthy SS, Omar S, Parham GP, Pramesh CS, Riviello R, Rodin D, Santini L, Shrikhande SV, Shrime M, Thomas R, Tsunoda AT, van de Velde C, Veronesi U, Vijaykumar DK, Watters D, Wang $\mathrm{S}, \mathrm{Wu} \mathrm{YL}$, Zeiton $\mathrm{M}$ and Purushotham A: Global cancer surgery: delivering safe, affordable and timely cancer surgery. Lancet Oncol 16: 1193-1224, 2015.
40 Hong DG, Lee YS, Park NY, Chong GO, Park IS and Cho YL: Robotic uterine artery preservation and nerve-sparing radical trachelectomy with bilateral pelvic lymphadenectomy in earlystage cervical cancer. Int J Gynecol Cancer 21: 391-396, 2011.

41 Olaitan A and McCormack M: Centralisation of services for the management of ovarian cancer: arguments for. BJOG 114: 11881190, 2007.

42 Crawford SM and Brunskill PJ: Centralisation of services for the management of ovarian cancer: arguments against. BJOG 114: 1183-1185; discussion 1186-1187, 2007.

43 Kyrgiou M, Koliopoulos G, Martin-Hirsch P, Arbyn M, Prendiville W and Paraskevaidis E: Obstetric outcomes after conservative treatment for intraepithelial or early invasive cervical lesions: systematic review and meta-analysis. Lancet 367: 489-498, 2006.

44 Kyrgiou M, Mitra A, Arbyn M, Stasinou SM, Martin-Hirsch P, Bennett $\mathrm{P}$ and Paraskevaidis E: Fertility and early pregnancy outcomes after treatment for cervical intraepithelial neoplasia: systematic review and meta-analysis. BMJ 349: g6192, 2014.

45 Kyrgiou M, Athanasiou A, Paraskevaidi M, Mitra A, Kalliala I, Martin-Hirsch P, Arbyn M, Bennett P and Paraskevaidis E: Adverse obstetric outcomes after local treatment for cervical preinvasive and early invasive disease according to cone depth: systematic review and meta-analysis. BMJ 354: i3633, 2016.

46 Kyrgiou M, Mitra A, Arbyn M, Paraskevaidi M, Athanasiou A, Martin-Hirsch PP, Bennett P and Paraskevaidis E: Fertility and early pregnancy outcomes after conservative treatment for cervical intraepithelial neoplasia. Cochrane Database Syst Rev: CD008478, 2015.

47 Kyrgiou M, Athanasiou A, Kalliala IEJ, Paraskevaidi M, Mitra A, Martin-Hirsch PP, Arbyn M, Bennett P and Paraskevaidis E: Obstetric outcomes after conservative treatment for cervical intraepithelial lesions and early invasive disease. Cochrane Database Syst Rev 11: CD012847, 2017.

48 Kyrgiou M, Valasoulis G, Stasinou SM, Founta C, Athanasiou A, Bennett P and Paraskevadis E: Proportion of cervical excision for cervical intraepithelial neoplasia as a predictor of pregnancy outcomes. Int J Gynaecol Obstet 128: 141-147, 2015.

49 Kasuga Y, Miyakoshi K, Nishio H, Akiba Y, Otani T, Fukutake M, Ikenoue S, Ochiai D, Matsumoto T, Tanaka K, Minegishi K, Kuji N, Roberts R, Aoki D and Tanaka M: Mid-trimester residual cervical length and the risk of preterm birth in pregnancies after abdominal radical trachelectomy: a retrospective analysis. BJOG 124: 1729-1735, 2017.

50 Kyrgiou $\mathrm{M}$ and Bennett P: Can we prevent preterm birth after radical trachelectomy? BJOG 124: 1737, 2017.

Received March 26, 2018

Revised April 13, 2018

Accepted April 18, 2018 